\title{
A TRADUÇÃO DE JOGOS DE PALAVRAS EM UM CORPUS LITERÁRIO: UMA REVISÃO DO MODELO DE DELABASTITA COM O AUXÍLIO DA LINGUÍSTICA DE CORPUS
}

\author{
Nilson Roberto Barros da Silva ${ }^{1 \times}$ \\ ${ }^{1}$ Universidade do Estado do Rio Grande do Norte, Mossoró, Rio Grande do Norte, \\ Brasil
}

Resumo

Este trabalho analisa a tradução de jogos de palavras em um corpus literário, o romance O Xangô de Baker Street (SOARES, 1995), traduzido para o inglês por Clifford Landers em 1997, e o faz com base no modelo (quadro de estratégias de tradução de jogos de palavras) apresentado por Delabastita (1996). O estudo utiliza a abordagem teórico-metodológica da Linguística de Corpus e se caracteriza como um "estudo direcionado pelo corpus" (TOGNINI-BONELLI, 2001). A análise das traduções demonstrou que o referido modelo dá conta apenas de parte dos procedimentos observados na tradução dos jogos de palavras investigados, e em decorrência disso, como resultado, o estudo propõe a sua ampliação por meio do acréscimo de quatro novas estratégias de tradução de jogos de palavras.

Palavras-chave: Linguística de Corpus; Corpus Literário; Estratégias de Tradução; Jogo de Palavras.

\section{THE TRANSLATION OF WORDPLAYS IN A LITERARY CORPUS: A REVIEW OF DELABASTITA'S FRAMEWORK BASED ON CORPUS LINGUISTICS}

Abstract

This paper analyzes the translation of wordplay from a literary corpus, the novel "O Xangô de Baker Street" (SOARES, 1995), translated into English by Clifford Landers in 1997, and does so based on the framework of Delabastita (1996) for wordplay's translation. The study uses the theoretical-methodological approach of Corpus Linguistics and is characterized as "corpus driven" (TOGNINI-BONELLI, 2001). The analysis of the translations showed that Delabastita's framework can cope with only part of the procedures observed in the translation of the wordplay investigated, and as a result, the study proposes to expand the

\footnotetext{
Possui Graduação em Letras, pela Universidade do Estado do Rio Grande do Norte - UERN (1997); Especialização em Planejamento Educacional, pela Universidade Salgado de Oliveira - UNIVERSO (1999); Especialização no Ensino da Língua Inglesa, pela Universidade do Estado do Rio Grande do Norte - UERN (2005); Mestrado Acadêmico Em Linguística Aplicada, pela Universidade Estadual do Ceará - UECE (2006) e Doutorado em Estudos Linguísticos e Literários em Inglês, pela Universidade de São Paulo - USP (2015). Atualmente é professor Adjunto IV da Universidade do Estado do Rio Grande do Norte. É líder do Grupo de Estudos da Tradução - GET/UERN, professor do Programa de Pós-Graduação em Ciências da Linguagem - PPCL/UERN. Tem experiência na área de Letras, com ênfase em Tradução, atuando principalmente nos seguintes temas: Ensino de Inglês como LE; Tradução; Linguística de Corpus. Seu e-mail é: nilsonbarros@uern. br. Registro Orcid: 0000-0001-6054-9386
} 
mentioned framework, by means of the addition of four new strategies for wordplays' translation.

Keywords: Corpus Linguistics; Literary Corpus; Translation Strategies; Wordplay. 


\section{Considerações iniciais}

Este artigo apresenta os resultados de uma investigação que culminou com a elaboração de minha tese de doutorado. $\mathrm{O}$ estudo parte da constatação de que há uma quantidade pouco expressiva de pesquisas envolvendo a análise da tradução de jogos de palavras (JPs), especialmente na direção português-inglês. Importa salientar que neste estudo compreende-se JP nos moldes do que propõe Delabastita (1996), para quem

[j]ogo de palavras é o nome genérico atribuído aos vários fenômenos textuais nos quais características estruturais da língua ou línguas utilizadas são exploradas com o objetivo de gerar um confronto comunicativamente significativo de duas (ou mais) estruturas linguísticas com formas mais ou menos semelhantes e sentidos mais ou menos diferentes. (DELABASTITA, 1996, p. 128, grifo do autor). ${ }^{1}$

Desse modo, considerando o número significativo de JPs no romance $O$ Xangô de Baker Street (SOARES, 1995), o estudo tem como objetivo geral analisar o tratamento dado a esses JPs pelo tradutor do romance para a língua inglesa, e o faz com o auxílio do aparato teórico-metodológico da Linguística de Corpus (LC).

Um aspecto importante dos JPs é que esse tipo de texto normalmente envolve humor (CHIARO, 1992), e, possivelmente em razão disso, pode ser observado em situações diversas de comunicação, tanto em textos orais como em textos escritos.

Ainda em relação aos JPs, Beckett (1957, apud DELABASTITA, 1996, p. 127) faz um gracejo inserindo-os em uma passagem bíblica do Gênesis: "no princípio havia o jogo de palavras"2. Ao comentar a frase, Delabastita (1996) propõe que os JPs são inerentes à própria linguagem e, portanto, "naturais à mente humana"3, 0 que sugere que os JPs vinculam-se às estruturas das línguas.

Se a proposição de Delabastita (1996) está correta, e se de fato, os JPs representam a manifestação linguística de um fenômeno que pode estar diretamente relacionado ao processamento da linguagem humana, então, o fato em si é motivo para que os JPs tenham um lugar nos estudos linguísticos. Nesse sentido, propõe-se uma reflexão acerca dos JPs e de sua tradução, tema central a esta pesquisa, qual seja: se, de fato, os efeitos e sentidos dos JPs relacionam-se diretamente à estrutura da língua em que são produzidos, então, como fazer para que esses efeitos e sentidos funcionem em outra língua?

Considerando o exposto, com vistas a atingir seu objetivo geral, o estudo apresenta dois objetivos específicos, o primeiro é verificar se as estratégias empregadas na tradução dos JPs do romance estudado são capazes de recriar seus efeitos e sentidos na língua-alvo. Esse objetivo baseia-se na hipótese ${ }^{4}$ de que não é possível garantir, em todos os casos de tradução de JPs, que os seus efeitos e sentidos funcionem igualmente na língua-alvo.

Por fim, com base na hipótese de que o modelo apresentado por Delabastita (1996) não dá conta de todas as estratégias de tradução usadas pelo tradutor 
do romance O Xangô de Baker Street para o inglês, pretende-se, como segundo objetivo específico, fazer a revisão do referido modelo e propor a sua ampliação por meio da inserção de novas estratégias de tradução de JPs.

\section{A tradução literária}

Conforme observa Lambert (1998), ao se falar em tradução literária, tanto o conceito de "tradução" quanto o de "literário" são dados como consensuais; entretanto, como assegura o autor, são conceitos que, além de não serem simples, não são bem definidos em nenhuma cultura (CINTRÃO, 2009 e ARROJO, 2002).

Deixando-se de lado, por um momento, o aspecto conceitual da "tradução" em si para deter-se na definição de "tradução literária", observa-se que, para uma tradução ser considerada "literária" é preciso que se realize com textos literários. Pode parecer simples, à primeira vista, no entanto, como aponta Lambert (1998), não o é. Afinal, o que, de fato, pode-se considerar "literário"? A "literariedade" é inerente ao próprio texto dito "literário"? Quais as características que diferenciam um texto "literário" de um "não literário"? Quanto aos JPs que serão analisados na seção 5 deste artigo, sendo oriundos de um livro reconhecido como "romance", poderiam ser considerados "JPs literários"?

A esse respeito, Cintrão (2009) apresenta um paralelo entre as posições de Jakobson (1995) e Arrojo (2002), o qual, embora não pretenda resolver a questão epistemológica que envolve a dicotomia "literário" vs. "não literário", configura-se como um ponto de partida interessante para futuras investigações:

A perspectiva de Jakobson implica que haveria fatores intrínsecos e, portanto, traços perceptíveis na materialidade do texto, que nos permitiriam atribuir-lhe o status de "literário". Em contraste, na perspectiva de Arrojo (1999), a "literariedade" de um texto se fundaria, de fato, em bases convencionais e culturais que cercam o fenômeno da recepção, não havendo elementos textuais intrínsecos e estáveis, temáticos ou de intencionalidade do autor, que permitissem diferenciar objetivamente textos literários de não literários, para além da relação peculiar que o leitor estabelece com o texto. (CINTRÃO, 2009, p. 2724).

Conforme exposto, se, para Jakobson (1995), a "literariedade" é inerente ao próprio texto, para Arrojo (2002) não há elementos nele que a determinem objetivamente, de modo que a "literariedade" seria o resultado de uma convenção estabelecida pela cultura da comunidade linguística em uma determinada época e espaço. Nesse sentido, no âmbito deste artigo, são considerados "literários" os textos que, de alguma forma, assim se autodenominam, são apresentados por seus autores ou apresentam características geralmente aceitas pelas pessoas em geral, como poemas, romances, contos etc. Consequentemente, a "tradução literária" refere-se à tradução dos textos aceitos pelas pessoas como "literários".

No tocante ao status da tradução literária, de acordo com o que observa Arrojo (2002) - que discute, entre outros temas, o preconceito e a inferioridade 
em torno desse tipo de tradução - há quem considere a tradução literária como uma atividade que descaracteriza e destrói os textos. Esse é o caso, por exemplo, do poeta americano Robert Frost (1874-1963), para quem uma "boa poesia" é intraduzível e que afirma ser a "boa poesia" exatamente aquilo que se perde em uma tradução (ARROJO, 2002).

Por outro lado, se o debate a respeito da possibilidade e inferioridade da tradução literária transita pela via do "melancólico" (LAGES, 2002), não é necessário partir daí para adentrar as portas do "jocoso", é o que revela a observação de Antunes (1991) acerca de uma nota escrita por Oswald de Andrade na primeira edição de Serafim Ponte Grande (1972):

Oswald de Andrade brincou ao anotar no verso da página de rosto da primeira edição de Serafim Ponte Grande a seguinte advertência: "Direito de ser traduzido, reproduzido e deformado em todas as línguas" (1, p. 97). Embora a nota [...] queira ridicularizar o copyright editorial, não há dúvida de que ela comporta uma certa concepção de tradução, apontando evidentemente para a dificuldade de se manter a chamada integridade original de uma obra literária em texto traduzido. (ANTUNES, 1991, p. 1).

Todavia, se a tradução literária tem sido vista como atividade de menor valor por uma quantidade expressiva de pensadores, ao longo dos séculos, também há aqueles que a veem como meio de desenvolvimento cultural do indivíduo e mesmo de uma sociedade. Os alemães, segundo Milton (1998), especialmente entre os séculos XVIII e XIX, têm os tradutores como uma espécie de semideuses e profetas, capazes de proporcionar "infinitas possibilidades através da introdução das formas e das ideias das grandes literaturas do mundo." (MILTON, 1998, p. 2).

É nesse sentido que grandes pensadores alemães do período citado dirigem à tradução e ao tradutor um olhar de quase devoção, em contraste com o observado, até então, em outras partes da Europa. Conforme atesta Milton (1998), Herder (1877), por exemplo, vê o tradutor como a "estrela da manhã", responsável por introduzir a literatura em uma nova era, enquanto para Goethe (1977), tratase do mediador em um "comércio espiritual". Ainda de acordo com Milton (1998), Schlegel (1962) vê na tradução a mais elevada das escrituras, ao passo que Novalis (1968) a coloca acima do original, da mesma forma que Breitinger (1966) e Humboldt (1909) destacam na tradução o aspecto relacionado ao desenvolvimento intelectual do ser humano. Milton (1998) assevera ainda que para Humboldt (1909) o texto traduzido é capaz de proporcionar ao indivíduo experiências que ele não poderia ter de outra forma, e que Breitinger (1966), por sua vez, encontra no ato de traduzir a melhor maneira de aprender a pensar.

Com efeito, não é apenas entre os clássicos alemães que se encontram os que veem a tradução literária para além da melancolia e inferioridade. Landers (2001), por exemplo, ao responder à questão "por que tradução literária?", afirma que dentre todas as formas de tradução, somente a literária proporciona ao tradutor o privilégio de trabalhar com as grandes obras da literatura universal. Além disso, observa que há tradutores para quem o "simples" desafio 
intelectual proporcionado pela tradução literária é um elemento importante por si mesmo, como é o caso, por exemplo, de se encontrar um equivalente para um JP da língua-fonte.

Diante do exposto, observa-se que nem tudo o que se pensa sobre tradução literária está imerso em uma realidade de marginalização, inferioridade e impossibilidade. E que a visão pessimista sobre tradução tem origem em um tipo de pensamento (sobre tradução) que não considera suas diferenças em relação ao texto-fonte, mas a busca de uma "semelhança ingênua" que, em muitos casos, está fadada a não se conseguir. Um exemplo do que aqui se trata como a busca de uma "semelhança ingênua" reflete-se na crença de que quando não se traduz literalmente forma e conteúdo em todos os tipos de textos (inclusive JPs linguísticos), a tradução é vista como "infiel” ao original.

Consideradas essas questões, destaca-se a pertinência da proposta de redefinição da tradução literária nos moldes do que apresenta Arrojo (2002). Para a autora, que se contrapõe à noção de Leopardi (1798-1837), segundo a qual "[a]s ideias estão contidas e praticamente engastadas nas palavras como pedras preciosas num anel" (LEOPARDI apud ARROJO, 2002, p. 29), a redefinição de tradução literária pressupõe uma mudança na noção de "literário". Assim, Arrojo (2002) propõe a percepção do "literário" como resultado da decisão de uma comunidade linguística, válida para um período de tempo indeterminado. Para a autora, o "literário" reside na forma como se lê, ou seja, o "literário" é uma "estratégia de leitura" (ARROJO, 2002, p. 31), em oposição à ideia da existência de características inerentes ao próprio texto.

Desse modo, portanto, a tradução de um texto dito "literário" (ou "não literário") será sempre o resultado da interpretação do tradutor. Será sempre o resultado daquilo que o tradutor, como leitor privilegiado, acredita ser o texto. Daí pode-se observar que outro ponto de confluência entre a tradução literária e a tradução de JPs reside no fato de que tanto uma quanto a outra dependem de certos posicionamentos (dos tradutores), capazes de definir a própria possibilidade ou impossibilidade da tradução. Em outras palavras, é a noção subjacente à prática do tradutor que define, por exemplo, como se traduz um poema. De modo semelhante, são as concepções teóricas (conscientes ou não) do tradutor que definem se é possível a tradução de um JP e, em sendo, como se realizará. É a esse respeito, portanto, que se discute na seção a seguir.

\section{A tradução de JPs}

Ao discutir a tradução de JPs, Delabastita (1996) traz à tona uma questão central a esta pesquisa: a própria traduzibilidade dos JPs. Além disso, discute aspectos teóricos subjacentes à tradução de JPs e à tradução de qualquer tipo de texto, como a proposição de que a ideia de traduzibilidade está sempre atrelada à visão de tradução de cada indivíduo, conforme se verifica na citação a seguir: 
Na verdade, há muito mais em questão do que a simples pergunta: jogos de palavras são traduzíveis? Para começar, qualquer resposta a essa questão tende a ser teoricamente tendenciosa na medida em que vai depender do tipo de tradução que se tem em mente (em termos de tipos e graus de equivalência, bem como de gêneros e situações comunicativas), mas também da própria posição do falante em face à atividade de tradução (se a pessoa está falando como um professor de tradução, como um tradutor profissional, um crítico, um teórico, um historiador, um filósofo da linguagem). ${ }^{5}$ (DELABASTITA, 1996, p. 127, grifo do autor).

A tradução de JPs, da mesma forma que a tradução de enunciados humorísticos em geral, nas suas mais diversas formas de manifestação, bem como a tradução literária, conforme visto na seção anterior, tem sido objeto de debates (às vezes de controvérsias) tanto no âmbito dos Estudos da Tradução quanto fora dele. Nessas circunstâncias, ressalta-se a pertinência da discussão apresentada por Delabastita, na citação acima, não se trata de uma simples questão de possibilidade ou impossibilidade de traduzir. Como afirma o autor, há bem mais em jogo. Os resultados, as estratégias e a própria realização, não apenas da tradução de JPs, mas também de poesia ou de humor em geral, entre outros, encontram-se intimamente relacionados àquilo que se julga ser "tradução".

É tendenciosa qualquer afirmação acerca da traduzibilidade de JPs, assim como é tendenciosa qualquer afirmação acerca da traduzibilidade de outros tipos de textos, inclusive daqueles que, aparentemente, não apresentam grandes desafios ao tradutor, como a maioria dos textos jornalísticos, cartas etc. Isso porque a tradução ocorre na língua, e essa não é um objeto de contornos bem definidos (ARROJO, 2002).

A tradução materializa-seem textose esses também apresentam fronteiras nem sempre bem demarcadas. Assim, a ideia que se tem de tradução e traduzibilidade, independentemente do tipo de texto, relaciona-se inevitavelmente à noção de texto "original". Por exemplo, se a ideia que se tem é a de que os sentidos presentes no texto "original" encontram-se fixos nas palavras, então, a tradução é possível entre línguas que possuam palavras correspondentes. Nesse caso, os sentidos seriam "transferíveis" entre uma língua e outra.

Se, por outro lado, a ideia de texto "original" é a de que os sentidos não se encontram fixos nas palavras, mas são construídos por meio de um processo sociocognitivo em que estão envolvidas tanto as palavras (textos) quanto as experiências de mundo do leitor, então, possivelmente, a ideia de tradução mais aceita será aquela em que os sentidos possam ser reconstruídos na língua-alvo, mesmo que de forma parcial, independentemente da existência de correspondentes diretos para todas as palavras do texto a ser traduzido.

Para estudiosos como Reiss e Vermeer (1996), a tradução de qualquer tipo de texto (inclusive a de JPs e a tradução literária, portanto) baseia-se na função que desempenhará o texto traduzido. De modo geral, a ideia é que o texto traduzido funcione tão bem quanto o texto "original", sendo assim, para esses autores, questões como a transferência $v s$. reconstrução dos sentidos, ou fidelidade $v s$. liberdade encontram-se em segundo plano. 
A propósito de tradução e de JP, Redfern (1997, p. 264) postula que a atividade de tradução em si, independentemente do tipo de texto, envolve o "lidar com jogos de palavras."' Implica (por parte do tradutor) ter o que chama de punning mind, isto é, uma mente aberta a grande número de associações e que as realize de forma rápida.

Por sua vez, Toury (1997), que discute a questão da traduzibilidade de spoonerismos (a troca de sílabas entre duas palavras), em primeiro lugar, e de JPs, por extensão, compreende a traduzibilidade como algo que se relaciona principalmente a questões de aceitabilidade; ou seja, o status do gênero textual na comunidade cultural onde está inserido é decisivo para que seja aceito como texto, traduzido ou não. Por outro lado, o autor ressalta que a noção de traduzibilidade de textos em geral tem sido tratada como uma ideia de gradação, isto é, tradução e traduzibilidade não são aspectos estanques que simplesmente se realizam ou não, mas que se realizam até certo ponto.

Ainda no âmbito da questão da traduzibilidade, observa-se que em capítulo dedicado à tradução de JPs, Chiaro (1992) adota a noção de equivalência dinâmica $(\text { NIDA, 1964) })^{7}$ para resolver o problema de tradução na charada "[w] hat's black and white and red (read) all over?", 8 que envolve as palavras da língua inglesa red (vermelho) e read (particípio passado do verbo read - "ler"), cujas pronúncias são idênticas (CHIARO, 1992). Nessas circunstâncias, depreende-se que o conceito de intraduzibilidade para Chiaro (2004) refere-se especialmente à complexidade da tarefa, o que ocorre, por exemplo, quando há ausência de equivalência formal.

Outros estudiosos da tradução de JPs, como Asimakoulas (2004) e Veisbergs (1997), não apenas entendem a traduzibilidade de JPs como algo possível, mas também apresentam estratégias voltadas à tradução desse tipo de texto. Asimakoulas (2004), além de sugerir a pertinência das estratégias de Delabastita (1993) para a tradução de JPs, afirma, com base em um estudo realizado com legendas de filmes de comédia, que separar os componentes de um enunciado humorístico pode ser uma estratégia útil e um exercício para encontrar alternativas de tradução. Para o autor, trata-se de uma estratégia que pode ser aplicada não só "ao humor baseado no registro, em que longos trechos são editados no processo de legendagem, mas também aos jogos de palavras (verbo-pictóricos) envolvendo unidades bem menores" (ASIMAKOULAS, 2004, p. 840) ${ }^{9}$.

Veisbergs (1997), por sua vez, apresenta uma série de estratégias de tradução para um tipo especial de JPs que se baseia em expressões idiomáticas. Um exemplo de estratégia utilizada pelo autor é a "compensação", isto é, a inserção de um elemento em algum lugar do texto-alvo, com o objetivo de compensar o efeito perdido em um JP do texto-fonte.

Algumas dasestratégias detraduçãodeJPsbaseadosemexpressõesidiomáticas apresentadas por Veisbergs (1997) são: transformação em expressão idiomática equivalente (equivalent idiom transformation); tradução por empréstimo (loan translation); transformação em expressão idiomática análoga (analogue idiom transformation); substituição (substitution), entre outras. Conforme se observa, as estratégias de tradução de Veisbergs (1997) são direcionadas a um tipo especial de 
JPs, aqueles que se baseiam em expressões idiomáticas, e isso limita, naturalmente, o campo de abrangência dessas estratégias. Dessa forma, embora considerando relevante para o campo da tradução de JPs a contribuição de Veisbergs (1997) e dos demais autores discutidos, este trabalho baseia-se no modelo apresentado por Delabastita (1996), cujas estratégias de tradução aplicam-se a qualquer tipo de JP, como se verifica a seguir.

Delabastita (1996) apresenta oito estratégias para a tradução de JPs, conforme o modelo que segue ${ }^{10}$ :

JP $\rightarrow$ JP: o JP do texto-fonte é traduzido por um JP do texto-alvo, que pode diferir do JP do texto-fonte, em termos de estrutura formal, estrutura semântica, ou função textual.

$J P \rightarrow$ Não JP: o JP é traduzido por uma frase em que não há JP. A frase pode preservar seus dois sentidos, mas em um texto em que não há JP, ou selecionar um dos sentidos em detrimento do outro. Pode também ocorrer que ambos os componentes do JP sejam traduzidos de forma completamente diferente do JP do texto-fonte.

$\mathrm{JP} \rightarrow \mathrm{RRR}$ (Recurso Retórico Relacionado): o JP é substituído por um recurso retórico a ele relacionado, como repetição, aliteração, rima, referências diversas, ironia, paradoxo etc., que tem como objetivo recapturar o efeito do JP do textofonte.

$\mathrm{JP} \rightarrow$ Zero: o trecho que contém o JP é simplesmente omitido no texto-alvo.

JP TF = JP TT: o tradutor reproduz o JP do texto-fonte e, na medida do possível, seu contexto imediato, na forma original, sem, de fato, traduzi-lo. Em outras palavras, o JP do texto-fonte é transcrito no texto-alvo.

Não JP $\rightarrow$ JP: o tradutor insere um JP em partes do texto em que não há JP no texto-fonte. Esse procedimento ocorre principalmente como forma de compensação, cujo objetivo é contrabalançar a perda de JPs no texto-alvo.

Zero $\rightarrow$ JP: o tradutor adiciona material textual totalmente novo contendo JP, sem justificativa aparente no texto-fonte. A estratégia é utilizada especialmente como um recurso compensatório. Diferentemente da estratégia de tradução Não $\mathrm{JP} \rightarrow \mathrm{JP}$, em que o tradutor insere um JP em partes do texto onde não há JP no texto-fonte, na estratégia Zero $\rightarrow$ JP o tradutor cria um texto totalmente novo (um parágrafo inteiro, por exemplo), com a finalidade de ali inserir um JP.

Técnicas Editoriais: notas de rodapé ou de fim de documento, comentários em prefácios e posfácios, notas do tradutor, apresentação de soluções diferentes e/ou complementares para o mesmo problema do texto-fonte etc. Embora as técnicas editoriais sejam apresentadas por Delabastita (1996) como estratégias de tradução, na verdade são usadas principalmente para comunicar fatos acerca do processo e do resultado da tradução.

Das estratégias apresentadas, as cinco primeiras descrevem procedimentos tradutórios a partir de JPs (por exemplo, JPs previamente identificados em textos originais). São elas: JP $\rightarrow \mathrm{JP}$; JP $\rightarrow$ não JP; JP $\rightarrow$ RRR (Recurso Retórico Relacionado); JP $\rightarrow$ Zero e JP TF $=$ JP TT. Por outro lado, as três últimas estratégias 
não partem de JPs propriamente, mas da ausência desses em determinado trecho do texto-fonte, em contraste com o texto-alvo. São elas: Não JP $\rightarrow$ JP; Zero $\rightarrow$ JP e Técnicas Editoriais.

Esta pesquisa, por sua vez, parte da análise de JPs que foram identificados por meio da exploração de linhas de concordância geradas a partir de itens da lista de palavras-chave do corpus de estudo em português. Em outras palavras, em função da metodologia aplicada, esta pesquisa parte da análise de JPs (previamente identificados), e não da ausência deles no texto-fonte. Sendo assim, as cinco primeiras estratégias apresentadas por Delabastita (1996) aplicam-se a esta investigação enquanto as três últimas não, já que não partem de JPs, mas de situações relacionadas à sua ausência no texto-fonte. Contudo, apresentou-se o quadro completo de estratégias de tradução de JPs por Delabastita (1996), e não apenas as cinco estratégias representadas no estudo, com o intuito de propiciar a visão geral da proposta do autor. São essas, portanto, as categorias usadas na análise empreendida nesta investigação. Na seção a seguir, são apresentados os materiais e métodos usados na seleção dos JPs analisados, bem como um quadro contendo os JPs (texto-fonte e texto-alvo) identificados no corpus.

\section{Materiais e métodos}

Este trabalho adota o aparato teórico-metodológico da LC, notadamente para a seleção e análise dos dados, e se insere nos chamados "estudos direcionados pelo corpus”, conforme discutido por Tognini-Bonelli (2001). Nessa perspectiva, o pesquisador inicia a exploração do corpus de estudo sem partir de uma hipótese previamente construída, pois é a exploração do corpus que fornece elementos para a sua construção. Em razão disso, ressalta-se que as hipóteses mencionadas na introdução deste artigo foram construídas ao longo da pesquisa, com base nos dados apresentados pelo corpus.

O conceito de LC utilizado é aquele apresentado por Bowker e Pearson (2002, p. 9), que a definem como

[...] uma abordagem ou metodologia para o estudo do uso da língua. Trata-se de uma abordagem empírica que envolve o estudo de exemplos do que as pessoas de fato dizem, em vez de criar hipóteses sobre o que elas poderiam ou deveriam dizer. A Linguística de Corpus também faz uso extensivo da tecnologia computacional, o que significa que os dados podem ser manipulados de uma forma que seria simplesmente impossível quando se lida com material impresso. ${ }^{11}$

Inerente à noção de LC está a noção de "corpus", que, no âmbito desta abordagem, é entendido como um conjunto de dados linguísticos autênticos, isto é, produzidos em situações reais de comunicação, e são compilados com base em critérios predefinidos, principalmente para fins de pesquisa e apresentados, necessariamente, em formato eletrônico (BERBER SARDINHA, 2004; TAGNIN, 2013). 
O corpus de estudo desta pesquisa é constituído do romance $O$ Xangô de Baker Street (SOARES, 1995) e respectiva tradução para o inglês, A Samba for Sherlock, realizada por Clifford Landers em 1997. Os dados foram extraídos com base na análise da lista de palavras-chave do corpus de estudo e de linhas de concordância produzidas a partir das 60 palavras com maior chavicidade ${ }^{12}$ no corpus. A lista de palavras-chave e linhas de concordância foram geradas por meio do programa WordSmith Tools 6.0 (SCOTT, 2012) .

A análise das linhas de concordância geradas a partir das dez primeiras palavras da lista de palavras-chave do corpus revelou a existência de JPs envolvendo nomes próprios. Esse fato despertou o interesse em explorar mais linhas de concordância geradas a partir das demais palavras da lista de palavraschave. Assim, outros JPs foram identificados no corpus, embora nem todos fossem elaborados com nomes próprios. Ao final da exploração das linhas de concordância geradas com as 60 primeiras palavras da lista de palavras-chave foram identificados $21 \mathrm{JPs}$, dos quais sete envolvem nomes próprios e 14 não envolvem nomes próprios em sua elaboração. Esses resultados levaram-nos a investigar os JPs do corpus, com a intenção de verificar o tratamento dado pelo tradutor para a língua inglesa. A análise revelou ainda que, dos 21 JPs identificados, 14 são traduzidos por meio de estratégias compatíveis com aquelas presentes no modelo apresentado por Delabastita (1996) enquanto sete são traduzidos por meio de estratégias não contempladas no referido modelo. Segue a lista dos 14 JPs identificados no corpus e que são traduzidos de acordo com as estratégias apresentadas por Delabastita (1996), os quais não são discutidos neste artigo em razão da limitação de espaço.

\section{JPs traduzidos de acordo com a estratégia de tradução JP $\rightarrow$ JP}

\section{Vida fácil}

TF: Carolina haveria de seguir a dificílima vida fácil das prostitutas.

TA: Carolina would surely have had to take up the exceedingly arduous easy life of the prostitute.

\section{Chope dos Mortos}

TF: Mais chope para os vivos, no "Chope dos Mortos!" - pediu Alberto Fazelli. TA: "More beer for the living in the Beer Hall of the Dead!" requested Alberto Fazelli.

\section{Mi de Miguel}

TF: Eufórico, ele soletra aos ventos, na solidão da madrugada: MI, de Miguel, SOL de Solera, LA de Lara, RÉ, de Recanto de Afrodite, o nome da livraria, um toque de gênio.

IT: In his euphoria he spells to the winds, in the solitude of early morning: mi for Miguel, sol for Solera, la for Lara, re for Aphrodite's Retreat, the name of the bookstore, a stroke of genius. 


\section{Homem}

TF: -Tem dois homens aí fora querendo falar com a sinhá.

- E o que querem?

- Não sei, sinhá. Só sei que um fala uma língua esquisita e o outro é portuga. O portuga fica me dizendo: "Eu sou homem, eu sou homem".

Que ele é homem eu já vi.

Imediatamente, a baronesa entendeu que o "homem" era "Holmes".

TA: - There're two men outside wanting to speak to maim.

- What do they want?

- I don't know, ma'am. I only know one of them speaks some funny language and the other is a Portuguese. The Portuguese keeps telling me "I'm home, I'm home". Does he think he lives here?

Immediately, the baroness understood that 'home' was 'Holmes'.

\section{Seis alferes}

TF: - Je ne me mêle pas de ces affaires... - disse Sarah com um sorriso.

- O que foi que ela falou?- perguntou avidamente Pardal Mallet, da outra ponta da mesa.

Alberto Fazelli traduziu de ouvido: - Ela viu o Mello com seis alferes.

TA: -Je ne me mêle pas de ces affaires... said Sarah, smiling.

What did she say? -Pardal Mallet asked eagerly, from the other end of the table.

Alberto Fazelli translated as he had heard: -she understands Mello has had seven affairs.

\section{À francesa}

TF: - Antes que alguém pudesse ajudá-la, ergueu-se agilmente, deixando o guardanapo cair ao chão. Saiu da sala, de estômago cheio mas leve como uma pluma, em direção à escada que levava aos seus aposentos. Alberto Fazelli recolheu o guardanapo, cheirou o pano como se fosse o lenço de rendas da mulher amada e sentenciou profundamente:

- Isto é o que se chama sair à francesa.

TA: Before anyone could help her, she stood up nimbly, allowing her napkin to fall to the floor. She left the room, light as a feather despite a full stomach, heading toward the stairs that led to her quarters. Alberto Fazelli picked up the napkin, sniffed the cloth as if it were the lace handkerchief of his beloved, and declared profoundly, "That is what is known as taking French leave."

\section{JPs traduzidos de acordo com a estratégia de tradução JP $\rightarrow$ não JP \\ Da Roda}

TF: Já se sabe quem é a rapariga?

- Já. Chama-se Carolina de Lourdes Calixto. Era da Roda.

- Percebo, mais uma prostituta - declarou Sherlock Holmes, pensando que "roda" era uma gíria que denominava a zona do meretrício.

TA: Is the girl's identity known? 
Yes. Her name is Carolina de Lourdes Calixto. She was from the Wheel.

I understand. Another prostitute, stated Sherlock Homes thinking that "wheel" was slang denoting the street of fallen women.

\section{Imortal}

TF: Este grande pensador, este Aristóteles moderno, principal expoente da filosofia positivista, apesar de morto, será, sem dúvida, sempre lembrado como o maior imortal do nosso século!

TA: This great thinker, this modern Aristotle, the foremost exponent of positivist philosophy, despite his death will beyond any doubt be forever remembered as the greatest immortal of our century!

Encontro de veículos

TF: ENCONTRO DE VEÍCULOS

Ontem, na rua da Alfândega, o tílburi no 104 sofreu tamanha pancada de uma carroça que ficou estragado em diversos lugares.

\section{TA: COLLISION OF VEHICLES}

Yesterday, on Alfândega Street, tilbury n ${ }^{\circ}$ I04 incurred a blow from a wagon sufficient to damage it in several places.

JP traduzido de acordo com a estratégia de tradução JP $\rightarrow$ RRR (Recurso Retórico Relacionado)

JP 'Cordiais saudações'

TF: Ainda me resta uma corda no violino. Falando em corda, cordiais saudações, nos dois sentidos.

TA: I still have one violin string remaining. Speaking of remaining, I remain yours truly.

\section{JP traduzido de acordo com a estratégia de tradução JP $\rightarrow$ zero}

JP 'Profundamente'

TF: Prefere o português: profundamente, profunda mente, mente profunda.

TA:

JPs traduzidos de acordo com a estratégia de tradução JP TF = JP TT

Merde

TF: Boa sorte nas suas investigações, ou, como nós de teatro dizemos na França, merde!

- Merde para a senhora também - respondeu Pimenta, dando um vigoroso aperto na mão da atriz.

TA: Good luck with your investigations, or, as we theater folk say in France, merde! Merde to you, too," replied Pimenta, shaking the actress's hand vigorously. 


\section{Capotes}

TF: Entusiasmados, eles lançavam suas capas ao chão e gritavam numa língua que achavam ser a de Victor Hugo: "Pisez! Pisez! Pour favour, pisez sur nos capotes, madame!", repetiam, sem saber que capotes, em francês, não eram “capas" e, sim, "preservativos.

TA: In their excitement, they had thrown their capes to the ground and shouted in a language they thought to be that of Victor Hugo: "Pisez! Pisez! Pour favour, pisez sur nos capotes, madame!" they repeated, not knowing that in French capotes meant not "capes" but "condoms.

\section{Petrópolis}

TF: Petrópolis seria o mausoléu perfeito para a grande puta. Petrópolis, cidade apodrecida pela corte. Petrópolis, Putrípolis, Putrópolis.

TA: Petrópolis would be the perfect mausoleum for the great whore. Petrópolis, a city putrefied by the court. Petrópolis, Putrípolis, Putrópolis.

Na seção 5 são discutidos os sete JPs do corpus traduzidos por meio de estratégias não contempladas no modelo de Delabastita (1996) e sugere-se a sua revisão e ampliação a partir da inserção de quatro novas estratégias de tradução de JPs.

\section{Discussão de JPs traduzidos por meio de estratégias não contem- pladas no modelo de Delabastita (1996) e proposta de ampliação do referido modelo}

A análise contrastiva dos procedimentos adotados pelo tradutor de $O$ Xangô de Baker Street revela o uso de estratégias tradutórias que não fazem parte do modelo apresentado por Delabastita (1996). Observa-se que o referido modelo dá conta de 14 JPs identificados no corpus desta pesquisa, mas não dá conta de outros sete JPs identificados.

Foram observados JPs traduzidos por meio das seguintes estratégias: JP $\rightarrow$ JP, como os JPs intitulados "Vida fácil", "Chope dos Mortos", "Mi de Miguel", "Homem", "Seis alferes" e "À francesa"; JP $\rightarrow$ Não JP, como os JPs "Da roda", "Imortal" e "Encontro de veículos"; JP $\rightarrow$ RRR (Recurso Retórico Relacionado), como o JP intitulado "Cordiais saudações"; JP $\rightarrow$ Zero, como o JP "Profundamente" e JP TF = JP TT, como os JPs "Merde", "Capotes" e "Petrópolis".

A seguir são apresentadas e discutidas quatro estratégias de tradução de JPs que representam uma proposta deste estudo para a ampliação do modelo sugerido por Delabastita (1996). As duas primeiras propostas de estratégias de tradução são desenvolvidas a partir da primeira estratégia apresentada por Delabastita (1996), a estratégia JP $\rightarrow$ JP, em que um JP do texto-fonte é traduzido por um JP da língua-alvo, podendo ser mais ou menos diferente do JP do textofonte, em relação à estrutura formal, estrutura semântica, ou função textual. As 
duas primeiras propostas de estratégias são JP $\rightarrow$ JP + EXPL e JP $\rightarrow$ AT $\rightarrow$ JP. As duas propostas seguintes desenvolvem-se a partir da estratégia de tradução JP TF = JP TT, constante do quadro proposto por Delabastita (1996). De acordo com essa estratégia, o tradutor reproduz o JP do texto-fonte e, na medida do possível, reproduz seu contexto imediato no texto da língua-alvo, sem, de fato, "traduzilo". As propostas de estratégias decorrentes são JP TT = JP TF + EXPL e JP TT $=\mathbf{J P}$ TF $-\mathrm{X}$.

\subsection{A estratégia $J P \rightarrow J P+E X P L$}

Leia-se: Jogo de palavras $\rightarrow$ Jogo de palavras + Explicação. Essa estratégia é semelhante à estratégia JP $\rightarrow \mathrm{JP}$ apresentada por Delabastita (1996), com a diferença que, nessa proposta, adiciona-se uma explicação ao texto-alvo. $\mathrm{O}$ texto explicativo, portanto, não se encontra no texto-fonte e não é um elemento constitutivo do JP do texto-fonte ou do texto-alvo.

Identificou-se, no corpus de estudo, um JP traduzido por meio da estratégia JP $\rightarrow$ JP + EXPL, o JP "Casa da mãe Joana", sobre o qual se discorre a seguir. No quadro que segue e nos demais presentes nesta seção, TF refere-se a "Textofonte" e TA refere-se a "Texto-alvo".

\section{JP Casa da mãe Joana}

\begin{tabular}{|l|l|}
\hline TF & $\begin{array}{l}\text { Isso aqui é o Passeio Público, cidadão, não é a casa da mãe Joana! - sentenciou } \\
\text { o guarda. } \\
\text { Holmes, que não conhecia a expressão, retrucou impassível: } \\
\text { - O nome da senhorita é Anna, não é Joana, e faça-me o favor de deixar a } \\
\text { senhora mãe dela fora disso. }\end{array}$ \\
\hline TA & $\begin{array}{l}\text { This is the Public Promenade, citizen, not Mother Joana's house!" declared the } \\
\text { policeman, using a slang term for a brothel. } \\
\text { Holmes, who was unfamiliar with the expression, retorted, the young lady's } \\
\text { name is Anna, not Joana, and kindly leave her mother out of this. }\end{array}$ \\
\hline
\end{tabular}

O JP "Casa da mãe Joana” ocorre durante uma discussão entre Sherlock Holmes e um policial, no Passeio Público do Rio de Janeiro. O casal Sherlock Holmes e Anna Candelária, tendo-se excedido na troca de carícias em um ambiente público e familiar, acaba chamando a atenção do policial responsável pela segurança do local. Durante a discussão bastante acalorada, Sherlock Holmes não consegue recuperar o sentido de uma expressão (casa da mãe Joana) usada pelo policial e acaba por criar um JP a partir dela.

Considerando-se que o JP apresenta formas semelhantes ("casa da mãe Joana" e "casa da mãe da Anna"), com pequenas diferenças entre si, além de sentidos diferentes, pode-se caracterizá-lo como "paronímia" (DELABASTITA, 1996). A forma "casa da mãe Joana" (usada pelo policial) é uma expressão conhecida por brasileiros e exprime sentido relacionado a "bagunça" ou "desordem" e também "prostituição". Sherlock Holmes, embora conhecedor do idioma, não conhece a 
expressão e a compreende como "casa da mãe da Anna". Para Sherlock Holmes, o policial estaria admoestando sua namorada, Anna Candelária, chamando a atenção para o fato de que o Passeio Público não é a casa de sua mãe (casa da mãe da Anna).

A tradução reconstrói o JP de modo semelhante ao que se procede com a estratégia JP $\rightarrow$ JP, porém, adiciona ao texto-alvo a explicação "using a slang term for a brothel" (usando uma gíria para "bordel"), o que altera a estratégia, nos moldes do que é apresentado por Delabastita (1996).

O primeiro trecho - 1)"Isso aqui é o Passeio Público, cidadão, não é a casa da mãe Joana! - sentenciou o guarda" - é traduzido por 1) "This is the Public Promenade, citizen, not Mother Joana's house!" declared the policeman". Conforme se verifica, o tradutor reconstrói o trecho de modo que o texto da língua-alvo se aproxima sobremaneira do texto da língua-fonte, realizando a recuperação semântica de seus elementos.

Seguindo-se a análise da estratégia de tradução empregada no JP, o que será tratado neste trabalho como segundo trecho, na verdade o é somente no texto da língua-alvo, e se refere à parte que define a estratégia de tradução proposta, JP $\rightarrow$ JP + EXPL. A parte do texto-fonte 2) “ $\varnothing$ ”, em que o símbolo “ $\varnothing$ ” representa "vazio", é "representado" no texto-alvo como 2) "using a slang term for a brothel" (usando uma gíria para "bordel"). Ou seja, "2)" indica que o tradutor inseriu um texto explicativo no texto da língua-alvo, o qual, obviamente, não se encontra no texto da língua-fonte.

O trecho subsequente - 3) "Holmes, que não conhecia a expressão, retrucou impassível" - é traduzido por 3) "Holmes, who was unfamiliar with the expression, retorted,". O trecho em inglês apresenta a recuperação semântica dos elementos do trecho em português, exceto o último elemento, o adjetivo "impassível". Observase, ainda, que, no texto-fonte, esse trecho é separado pelos sinais gráficos "dois pontos" e "travessão", e ocorre em parágrafos diferentes. No texto-alvo, por sua vez, o trecho é unido ao trecho subsequente, formando apenas um período, mais longo, no mesmo parágrafo.

No último trecho, 4) "O nome da senhorita é Anna, não é Joana, e faça-me o favor de deixar a senhora mãe dela fora disso", o tradutor recupera o sentido dos elementos da frase, adaptando, onde necessário, sua estrutura, de modo que o texto continue "natural" na língua-alvo. O texto traduzido é 4) "the young lady's name is Anna, not Joana, and kindly leave her mother out of this".

Portanto, considerando que a estratégia usada na tradução do JP adiciona uma explicação ao texto-alvo, e que essa explicação não faz parte dos elementos que compõem o JP propriamente dito (pois, se o fizesse, seria compatível com a estratégia JP $\rightarrow$ JP), propõe-se a estratégia JP $\rightarrow$ JP + EXPL.

Tanto quanto a estratégia JP $\rightarrow$ JP + EXPL, a estratégia que será apresentada a seguir, JP $\rightarrow$ AT $\rightarrow$ JP, também se desenvolve a partir da estratégia JP $\rightarrow$ JP, de Delabastita (1996). 


\subsection{A estratégia $J P \rightarrow A T \rightarrow J P$}

Leia-se: Jogo de palavras $\rightarrow$ Alteração textual $\rightarrow$ Jogo de palavras. Conforme sugerido, esta estratégia é semelhante à estratégia JP $\rightarrow \mathrm{JP}$ apresentada por Delabastita (1996), com a diferença de que nesta proposta o tradutor realiza a substituição de uma palavra no texto inteiro com o objetivo de viabilizar a tradução de um (ou mais) JP(s).

No corpus de estudo foram identificados dois JPs traduzidos por meio dessa estratégia, os JPs intitulados "Esperidiana" e "Orelhas", sobre os quais se discorre a partir deste ponto.

\section{JP Esperidiana}

\begin{tabular}{|l|l|}
\hline TF & $\begin{array}{l}\text { Ele costumava brincar com ela a respeito do seu nome: "Não é Esperidiana? } \\
\text { Então, espera que eu volto". }\end{array}$ \\
\hline TA & $\begin{array}{l}\text { He was in the habit of joking with her about her name. "Isn't it Paciência? So, } \\
\text { be patient until I come home." }\end{array}$ \\
\hline
\end{tabular}

O delegado Mello Pimenta, responsável pelas investigações dos crimes cometidos por Miguel Solera de Lara, não tem horários regulares de trabalho, em virtude da própria natureza da profissão. Embora sua esposa, Dona Esperidiana, não demonstre problemas em lidar com os horários do marido, o delegado tem o hábito de "brincar" com a semelhança de sentidos de seu nome. Essa semelhança é criada pelo próprio Mello Pimenta, e envolve as palavras "Esperidiana" e "esperar". É em uma ocasião de "brincadeira" desse tipo que o delegado pronuncia o JP em análise. O JP é construído, portanto, pelo delegado, que estabelece uma relação entre o nome de sua esposa, "Esperidiana", e o verbo "esperar". Para ele, o nome "Esperidiana" referir-se-ia a "aquela que espera", conforme se depreende do texto do JP.

No tocante à estratégia de tradução usada para reconstruir o JP na língua inglesa, a parte que representa o JP propriamente dito "Não é Esperidiana?" foi traduzido por "Isn't it Paciência?". Observa-se a substituição do nome da personagem "Esperidiana", do texto-fonte, pelo nome "Paciência", no texto-alvo, cuja motivação se discute a seguir, ao analisar-se a última parte do JP.

A última parte "Então, espera que eu volto" é reconstruída em inglês como "So, be patient until I come home". Nessa parte, o tradutor deixa transparecer a razão de ter substituído, no segundo trecho, o nome "Esperidiana" por "Paciência”. Como há uma "motivação" linguística na construção do JP na línguafonte, qual seja, a relação de sentido estabelecida a partir da forma das palavras "Esperidiana" e "esperar", o tradutor procura reconstruir o JP preservando essa relação. Para isso, dá primazia à forma do JP em detrimento do sentido do JP do texto-fonte. Assim, se o JP na língua-fonte explora a relação de sentido entre as formas "Esperidiana" e "esperar", no texto da língua-alvo o tradutor se vale de um tipo de relação semelhante e elabora o JP no texto da língua-alvo usando as formas "Paciência" e "be patient" (seja paciente). 
A opção do tradutor pelo efeito do texto na língua-alvo em detrimento do sentido do texto-fonte é declarada em entrevista concedida a Aguiar (2010), por exemplo, da mesma forma que pode ser verificada em publicação do próprio tradutor, em seu livro Literary translation: a practical guide, publicado em Nova York pela editora Multilingual Matters, em 2001. Ao comentar a tradução do JP "Homem", do romance O Xangô de Baker Street (A Samba for Sherlock) o autor/ tradutor assevera:

Em "A Samba", romance ambientado no Rio de Janeiro de 1886, quando o formidável detetive inglês chega para fazer uma visita, a ignorância de uma escrava da casa em relação aos sobrenomes ingleses se reflete em sua incapacidade de compreender a afirmação de Sherlock: "Eu sou Holmes", a qual ela entende "Eu sou homem, eu sou homem". "Que ele é homem eu já sei." É possível recuperar o humor na tradução? "Eu sou homo" foi rejeitado imediatamente, não por razões de pudor, mas porque a gíria para homossexual não havia sido registrada até a terceira década do século 20. Daí, a inspiração (?): "I'm home" (estou em casa), o que permite à escrava dizer: "Does he think he lives here?" "Será que ele pensa que mora aqui?» O sentido vai, o humor (espero) fica. ${ }^{13}$ (LANDERS, 2001, p. 58).

A tradução reconstrói o JP de modo semelhante ao que se observa na estratégia $J P \rightarrow J P$, de Delabastita (1996). Ocorre, entretanto, que, para fazê-lo, o tradutor toma uma decisão que altera a tradução do romance inteiro, isto é, substitui o nome "Esperidiana" por "Paciência", em todo o texto-alvo. Portanto, o tradutor não reconstrói, simplesmente, o JP, a partir dele mesmo, como ocorre na estratégia JP $\rightarrow$ JP, mas toma uma decisão que implica a alteração do texto de modo global, ou seja, ao traduzir o JP, o tradutor substitui uma palavra e essa palavra será substituída em todo o texto da língua-alvo. É desse modo, portanto, que se caracteriza a estratégia de tradução JP $\rightarrow \mathbf{A T} \rightarrow \mathbf{J P}$, em que "AT" refere-se à "Alteração textual" por meio da substituição de uma palavra no texto, conforme exposto acima.

Ressalta-se que os demais nomes de pessoas no texto do romance O Xangô de Baker Street mantêm formas idênticas no texto-fonte e no texto-alvo, inclusive nos casos em que os nomes constituem elementos integrantes de JPs, como ocorre, por exemplo, com o nome "Holmes" na citação apresentada. Isso torna evidente o fato de que a substituição do nome "Esperidiana" por "Paciência" no texto da língua-alvo acontece com o objetivo de viabilizar a reconstrução do JP.

Na sequência, discorre-se sobre o JP "Orelhas", o segundo identificado no corpus de estudo cujas estratégias de tradução são compatíveis com a proposta de estratégia JP $\rightarrow$ AT $\rightarrow$ JP apresentada nesta investigação.

\section{JP Orelhas} fundo, sempre soube que o néscio britânico jamais as ligaria a ele. Orelhas. Orelhas de livro. Livro, livreiro. Miguel Solera de Lara. O pobre tolo conhecia bem a língua, porém falava como um lusitano, para quem essas orelhas são abas. 


\begin{tabular}{|l|l|}
\hline TA & $\begin{array}{l}\text { All that is left is the flaps of skin. So obvious, the flaps. He guffaws again. Deep } \\
\text { inside, he always knew the half-witted Englishman would never link them to } \\
\text { him. Flaps. The flaps of a book. Book, bookseller. Miguel Solera de Lara. The } \\
\text { poor idiot knew the language well, but he spoke like a Portuguese, for whom } \\
\text { such flaps have a different name. }\end{array}$
\end{tabular}

Este JP localiza-se no capítulo 24, último do romance em análise. É pronunciado por Miguel Solera de Lara, a bordo do navio Kaikoura, que o conduz à Inglaterra, onde passará a residir. Antes de jogar ao mar as últimas provas de seus crimes, as orelhas extirpadas das moças assassinadas, Miguel declara, uma vez mais, para si mesmo, o seu desprezo pelo detetive Sherlock Holmes. Para o assassino, Holmes jamais ligaria as "orelhas" a ele, o livreiro, embora a palavra "orelha" refira-se também a uma parte dos livros, a chamada "orelha" de livro.

A tradução desse JP, bem como do JP discutido imediatamente antes (Esperidiana), remonta à discussão apresentada por Landers em seu livro "Literary translation: a practical guide" (2001). Trata-se de uma sugestão dirigida especialmente aos tradutores em formação, acerca da importância de se ler mais de uma vez a obra a ser traduzida, antes de se iniciar a tradução. Como afirma o autor, o livro é um reflexo de sua própria prática tradutória, portanto, o trabalho de tradução de $O$ Xangô de Baker Street também reflete, obviamente, a prática tradutória de Landers (2001), descrita em seu livro, direcionado à tradução literária.

Ao traduzir O Xangô de Baker Street, Landers demonstra muita familiaridade com o romance, e a impressão sobre essa familiaridade reside no fato de que Landers traduz a palavra "orelhas" por "flaps of skin" (pedaço de pele), em vez de "ears" (orelhas) em quase todo o romance, o que faz com um objetivo em mente: viabilizar a tradução do JP "Orelhas", o qual é elaborado por meio de um trocadilho entre as palavras "orelha", parte do corpo humano e "orelha" de livro.

O romance apresenta 35 ocorrências da palavra "orelhas", das quais 32 referem-se a "orelhas" humanas. A tradução de "orelhas" por "ears" dá-se apenas na última das 32 ocorrências da palavra "orelhas" com sentido de "orelhas humanas", logo após o trecho onde se situa o JP, localizado na parte final do romance. $\mathrm{Ou}$ seja, já não havia mais a necessidade de traduzir "orelhas" (humanas) por "flaps of skin" porque o JP já havia sido reconstruído, e o trecho onde se localiza havia ficado para trás.

A ideia de que a substituição de "ears" por "flaps of skin" no texto-alvo ocorre com vistas à recriação do JP "Orelhas" é confirmada posteriormente pelo tradutor, que, ao discutir estratégias de tradução em O Xangô de Baker Street, afirma:

Em A Samba for Sherlock, a palavra crucial para o desfecho [do JP] era totalmente diferente em português e inglês. Isso forçou uma modificação chave no texto traduzido: o serial killer arranca pedaços de pele de suas vítimas em vez de lhes arrancar as orelhas. Em razão disso, mudanças subsequentes fizeram-se necessárias - por exemplo, a frase dita em tom de gracejo "Não há de ser por ganância. Nenhuma das vítimas usava brincos" [...] tornou-se "Não deve ser porque ele é um colecionador de artes. Nenhuma das vítimas usava tatuagem. ${ }^{14}$ (LANDERS, 2001, p. 110). 
Decompondo-se o JP em partes, é possível observar os procedimentos adotados por Landers para lidar com os diferentes problemas de tradução no texto. Assim, o trecho "Restam as orelhas. Tão óbvias, as orelhas" é apresentada em inglês como "All that is left is the flaps of skin. So obvious, the flaps". Exceto pela palavra "orelhas", o restante do trecho é traduzido para o inglês recuperandose $o$ aspecto semântico de seus elementos.

Os trechos "Ele gargalha novamente" e "No fundo, sempre soube que o néscio britânico jamais as ligaria a ele" são traduzidos literalmente por "He guffaws again" e "Deep inside, he always knew the half-witted Englishman would never link them to him".

O trecho "Orelhas. Orelhas de livro. Livro, livreiro. Miguel Solera de Lara", por sua vez, também seria reconstruído literalmente, não fosse pela palavra "orelha", traduzida por "flaps", para viabilizar a reconstrução do JP em inglês, conforme discussão acima. A tradução é realizada, portanto, como "Flaps. The flaps of a book. Book, bookseller. Miguel Solera de Lara".

$\mathrm{O}$ último período do texto que compõe o JP será dividido em duas partes, com vistas a facilitar a sua análise. A parte "O pobre tolo conhecia bem a língua, porém falava como um lusitano" é traduzida literalmente por "The poor idiot knew the language well, but he spoke like a Portuguese".

A última parte, "para quem essas orelhas são abas", apresenta uma modificação em inglês, em virtude da adaptação realizada em todo o romance, em relação à palavra "orelhas". A sua tradução para o inglês é apresentada como "for whom such flaps have a different name".

Finalmente, o tradutor realiza a substituição das duas últimas palavras do trecho em português (são abas) porque a palavra que as precede (orelhas) foi traduzida por "flaps", que, por sua vez, é um dos correspondentes da palavra "abas", em inglês. Portanto, não faria nenhum sentido, especialmente no contexto do JP, traduzir a sequência "para quem essas orelhas são abas" por "for whom such flaps are flaps". Assim, o tradutor substitui as palavras finais "são abas" pela forma genérica "have a different name" (têm um nome diferente).

Diante do exposto, embora a estratégia de tradução empregada na reconstrução do JP em inglês seja semelhante à estratégia JP $\rightarrow$ JP de Delabastita (1996), observa-se que, ao reconstruir o JP "Orelhas" o tradutor tomou uma decisão que afeta o texto-alvo de forma global, o que não ocorre com a tradução dos demais JPs traduzidos por meio dessa estratégia, no corpus. Por essa razão, descreve-se a estratégia usada pelo tradutor como JP $\rightarrow \mathbf{A T} \rightarrow \mathbf{J P}$.

As duas propostas seguintes desenvolvem-se a partir da estratégia de tradução JP TF = JP TT, constante no modelo proposto por Delabastita (1996). De acordo com essa estratégia, o tradutor reproduz o JP do texto-fonte e, na medida do possível, reproduz seu contexto imediato no texto da língua-alvo, sem, de fato, "traduzi-lo". 


\subsection{A estratégia JP TT $=J P T F+E X P L$}

Leia-se: Jogo de palavras no texto-alvo $=$ Jogo de palavras no texto-fonte + Explicação. Esta estratégia é semelhante à estratégia JP TF = JP TT apresentada por Delabastita (1996), com a diferença de que nesta proposta adiciona-se uma explicação ao texto-alvo. $\mathrm{O}$ texto explicativo, portanto, não faz parte do texto-fonte e não é um elemento constitutivo do JP, propriamente dito, no texto-fonte nem no texto-alvo, embora passe a constituir o texto em que se insere o JP no texto-alvo.

Foram identificados no corpus de estudo, dois JPs traduzidos por meio da estratégia proposta. São eles: o JP “Caipirinha” e o JP “Viado só amanhã”, os quais são discutidos a seguir.

\section{JP Caipirinha}

\begin{tabular}{|l|l|}
\hline TF & $\begin{array}{l}\text { Qual deles, o grandão? - perguntou o rapaz, indicando Sherlock Holmes, } \\
\text { todo de branco. } \\
\text { - Não, o caipira grande está só bebendo. Quem preparou foi o menorzinho, } \\
\text { o caipirinha - respondeu o proprietário, batizando assim, para sempre a } \\
\text { exótica mistura. }\end{array}$ \\
\hline TA & $\begin{array}{l}\text { Which hick, the big one? asked the young man, indicating Sherlock Holmes, } \\
\text { who was dressed all in white. } \\
\text { No, the big caipira is just drinking it. The one who made it is the little hick, } \\
\text { the caipirinha, replied the owner. Thus was baptized the exotic mixture that is } \\
\text { Brazil's national drink. }\end{array}$ \\
\hline
\end{tabular}

Este JP é construído com os sentidos da palavra "caipirinha", que se refere, no texto, tanto a um homem dito "matuto", "da roça", quanto a uma bebida alcoólica. No romance, insere-se no diálogo que mantêm entre si o proprietário de um bar e o balconista. Os dois têm a atenção atraída pelas atividades e também pelas vestimentas de Watson e Sherlock Holmes, que entram no bar atendendo ao convite de Saraiva, médico legista que acabara de realizar a perícia no cadáver de mais uma das vítimas de Miguel Solera de Lara.

Alguns minutos antes, Saraiva observa que Holmes, também presente ao local da perícia, está tonto e indisposto, uma consequência das extravagâncias da noite anterior. $\mathrm{O}$ experiente legista sugere que o detetive prove uma cachaça, remédio infalível para aquele mal. No bar, Watson, ao sentir o cheiro forte da bebida, orienta Holmes a não tomar a cachaça pura, sugere ao amigo que a misture com gelo, açúcar e suco de laranja ou limão, "para compensar a queima produzida pelo álcool" (SOARES, 1995, p. 230).

O JP apresenta características do que Delabastita (1996) classifica como homonímia. O trocadilho, conforme apresentado acima, é construído com a palavra "caipirinha", que se refere, em primeiro lugar, a Watson, pelo fato de estar vestido como um chamado "caipira" e ser de estatura mais baixa em relação a Holmes. Holmes também é visto como "caipira" e é referido pelo proprietário do bar como "o caipira grande". 
O segundo significado da palavra "caipirinha", conforme indicado acima, é o de bebida, drink preparado com cachaça, açúcar e suco de fruta, especialmente limão. É nessa coincidência formal, portanto, que reside a homonímia, já que a palavra "caipirinha" serve tanto para designar o homem (ou mulher) "caipira" de baixa estatura quanto a bebida. Assim, têm-se duas palavras (estruturas linguísticas) com grafia e som idênticos, mas com significados diferentes.

Ressalta-se que, embora a palavra "caipirinha" seja grafada apenas uma vez no JP, e se refira à pessoa, ao homem "caipira", o autor Jô Soares induz o leitor a pensar no significado da palavra como uma bebida, a "caipirinha". Isso ocorre no final do JP, por meio da frase "[...] batizando assim, para sempre a exótica mistura" (SOARES, 1995, p. 231).

A tradução do JP para a língua inglesa ocorre da forma como segue: o trecho "Qual deles, o grandão? - perguntou o rapaz, indicando Sherlock Holmes, todo de branco" é traduzido por "Which hick, the big one? asked the young man, indicating Sherlock Holmes, who was dressed all in white".

Como indicado acima, o JP em português é construído com as palavras "caipira" e "caipirinha". Desde o início do trecho, o tradutor dá pistas ao leitor acerca do significado da palavra "caipira". Por exemplo, o texto em português começa com a pergunta do balconista ao proprietário do bar: "Qual deles, o grandão?" A tradução, por sua vez, está assim: "Which hick, the big one”? (Qual caipira, o grande?) Observe-se que o texto-fonte não traz um correspondente para a forma "hick" em inglês. Contudo, "hick" aparece não apenas aí, mas também na linha anterior, parte do texto não selecionada para compor o contexto do JP neste estudo. Naquela parte, o tradutor usa a palavra "hick" ao adicionar uma informação (parte em negrito) ao texto-fonte. O texto-fonte e o texto-alvo apresentam-se da forma como segue:

- "Não sei, uma invenção daquele caipira ali" - disse, apontando para o chapéu de vaqueiro de Watson.

- "I don't know, something invented by that caipira there", he said pointing to Watson's cowboy hat and using the Brazilian term for a hick.

A informação nova "and using the Brazilian term for a hick" (literalmente: $\mathrm{e}$ usando o termo brasileiro para um caipira), adicionada pelo tradutor, é referida como "interpolação" e discutida pelo próprio tradutor em seu trabalho "Literary translation, a practical guide". A respeito da "interpolação" como estratégia tradutória, Landers (2001, p. 94) afirma: "Outra maneira de transmitir informação essencial já conhecida do leitor da LF é a interpolação. Em sua forma básica, nada mais é do que acrescentar uma palavra ou frase explicativa, tão discreta quanto possível [...]"15.

O tradutor-autor segue usando trechos da tradução do livro "São Jorge dos Ilhéus" (The Golden Harvest), de Jorge Amado, para dar exemplos da estratégia. $\mathrm{O}$ trecho é apresentado conforme se encontra no livro traduzido para o inglês: 
[The celebration] was in Olivença, on Pontal Island, home of Salu, the paide-santo, or priest, of the blacks' fetishistic religion brought from Africa... Rosa, Martins' lover, also came. She is an aiô, a priestess, and dances in the middle of the site. (LANDERS, 2001, p. 94).

Literalmente: [A celebração] foi em Olivença, na Ilha Pontal, lar de Salu, o pai-de-santo, ou sacerdote, da religião supersticiosa dos negros trazida da África... Rosa, amante de Martins, também veio. Ela é uma aiô, uma sacerdotisa, e dança no meio do terreiro.

Landers (2001, p. 94) afirma que "Tudo o que está depois de 'pai-de-santo', na primeira sentença, é um acréscimo, como o é a frase explicativa 'a priestess'. Ambos são exemplos de interpolação. Se realizada cuidadosamente e com atenção ao fluxo rítmico da língua, a interpolação pode ser imperceptível”. ${ }^{16}$

A esse respeito, quando discute a tradução de JPs baseados em expressões idiomáticas, Veisbergs (1997) corrobora essa estratégia de tradução, a qual é referida como "Extensão" (Extension). Ao descrevê-la, o autor afirma: "Uma estratégia que é raramente mencionada, embora possa alcançar resultados interessantes, é a de se estender a tradução da expressão idiomática transformada, por meio da inserção de alguma informação explanatória adicional" (VEISBERGS, 1997, p. 165). ${ }^{17}$

Desse modo, no caso do trecho 1), em discussão, a "interpolação" é utilizada com o objetivo de informar o leitor do texto-alvo que a palavra "caipira" equivale a "hick", em inglês. Voltando ao texto selecionado para compor o JP, o trecho "Não, o caipira grande está só bebendo. Quem preparou foi o menorzinho, o caipirinha' é traduzido por 'No, the big caipira is just drinking it. The one who made it is the little hick, the caipirinha'.

O trecho apresenta a frase em português 'o caipira grande', que é traduzida por 'the big caipira'. Na última linha do texto, encontra-se a forma 'o menorzinho, o caipirinha', que é traduzida por 'the little hick, the caipirinha'. Como se pode observar, o tradutor mantém no texto da língua-alvo as formas 'caipira' e 'caipirinha', da língua-fonte, e utiliza uma interpolação para ajudar o leitor a compreender o sentido das palavras não traduzidas.

O trecho seguinte - "respondeu o proprietário, batizando assim, para sempre a exótica mistura" - é traduzido por "replied the owner. Thus was baptized the exotic mixture". A tradução reconstrói o sentido geral do trecho, sem, no entanto, manter a estrutura do texto-fonte.

Finalmente, a exemplo do modo como procede na linha anterior à parte selecionada para compor o contexto do JP, na última linha do trecho o tradutor adiciona outra explicação. Dessa vez com o intuito de deixar claro para o leitor o fato de que "caipirinha" é uma bebida "nacional do Brasil", isto é, uma bebida representativa do país. Portanto, o que no texto da língua-fonte pode ser representado por "vazio" (Ø), no texto da língua-alvo registra-se a inclusão de uma frase explicativa: "that is Brazil's national drink".

Portanto, de acordo com o exposto, ratifica-se a ideia de que o JP é traduzido de modo semelhante (mas não idêntico) ao que se procede quando utilizada a 
estratégia JP TF = JP TT (Delabastita, 1996); ou seja, traduz-se o trecho onde se encontra o JP, contudo, o JP propriamente dito é reproduzido (e não traduzido) no texto-alvo com a mesma forma encontrada no texto-fonte. Observa-se, todavia, que, no JP em análise, reproduzem-se no texto-alvo as palavras da língua portuguesa "caipira" e "caipirinha", elementos principais da elaboração do JP. Entretanto, além desses procedimentos, verifica-se que o tradutor insere uma explicação no texto-alvo, a qual é referida por Landers (2001) como "interpolação", a frase "that is Brazil's national drink". Assim, considera-se que a estratégia adotada na tradução do JP é semelhante ao que se observa em relação à estratégia JP TF = JP TT (Delabastita, 1996), contudo, uma vez que o tradutor adiciona uma explicação ao texto da língua-alvo, cria-se uma situação nova, não prevista na estratégia apresentada por Delabastita (1996); portanto, fica caracterizada a proposta de estratégia de tradução JP TT = JP TF + EXPL.

O segundo JP identificado no romance O Xangô de Baker Street, traduzido de acordo com a estratégia proposta JP TT $=$ JP TF + EXPL é o JP "Viado só amanhã”, o qual é discutido a seguir.

\section{JP Viado só amanhã}

\section{$\mathrm{TF}$}

O Alemão, cansado das penduras, tinha colocado um cartaz bem visível ao lado da caixa com os dizeres: VIADO SÓ AMANHÃ. O erro de grafia devia-se à origem germânica do proprietário, que invariavelmente trocava o $\mathrm{F}$ pelo $\mathrm{V}$.

The German, tired of putting things on the cuff, had posted a clearly visible sign beside the cash register saying: VIADO SÓ AMANHÃ (credit only tomorrow). TA What he didn't know was that in Portuguese "credit" was fiado, while viado was a slang term for a homosexual. The spelling error was due to the proprietor's Germanic origin: he invariably confused $v$ with $f$.

O JP "Viado só amanhâ" encontra-se no capítulo 8 do romance e funciona como um "recado" do proprietário do "Bar do Necrotério" aos clientes que costumam beber e não pagar a conta. O Bar do Necrotério também é conhecido como "Chope dos Mortos", o título de outro JP identificado no corpus, conforme se pode conferir no início da quinta seção.

No tocante à relação forma $v s$. sentido, o JP é compatível com o que Delabastita (1996) classifica como "paronímia", já que sua construção envolve formas semelhantes com uma pequena diferença, no início da primeira palavra, a troca das letras " $f$ " e "v". A sequência "VIADO SÓ AMANHÃ" é apresentada como se fosse "FIADO SÓ AMANHÃ" pelo proprietário do bar. Portanto, as formas apresentam semelhanças com base em sentidos diferentes, já que a primeira, "VIADO SÓ AMANHÃ", no uso coloquial, equivale a "homossexual só pode comprar amanhâ". Já a frase "FIADO SÓ AMANHÃ" refere-se a uma informação do proprietário do bar aos clientes, segundo a qual, "só há vendas no crédito (fiado) no dia seguinte (amanhã)".

A tradução do JP para o inglês segue o procedimento normalmente observado do tradutor no tocante à tradução do romance O Xangô de Baker Street 
para a língua inglesa, que, de modo geral, procura recriar o efeito do texto-fonte no texto da língua-alvo. Assim, o trecho "VIADO SÓ AMANHÃ" é repetido no texto da língua-alvo: "VIADO SÓ AMANHÃ". Nesse ponto, a estratégia de tradução é idêntica à estratégia JP TF = JP TT, conforme apresentada por Delabastita (1996), já que o JP do texto-fonte é repetido ipsis litteris no texto da língua-alvo. Ocorre, no entanto, que, após repetir o texto do JP propriamente dito, o tradutor insere um texto explicativo que não se encontra no texto-fonte. Desse modo, a parte que no texto-fonte é indicada como "vazio" (Ø), no textoalvo apresenta-se como "(credit only tomorrow). What he didn't know was that in Portuguese "credit" was fiado, while viado was a slang term for a homosexual".

Conforme se observa, a frase inteira no texto-alvo constitui, portanto, um texto explicativo que interfere na estratégia de tradução JP TF $=\mathrm{JP} \mathrm{TT}$, nos moldes do que apresenta Delabastita (1996). Dessa forma, em razão, exatamente, da existência do texto explicativo, a estratégia efetivamente adotada pelo tradutor é compatível com a estratégia proposta neste estudo, a estratégia de tradução: JP TT $=$ JP TF + EXPL.

A última estratégia proposta neste estudo também é desenvolvida com base na estratégia JP TF = JP TT para a tradução de JPs, nos moldes do quadro apresentado por Delabastita (1996), a estratégia JP TT = JP TF - X, que será discutida nas linhas que seguem.

\subsection{A estratégia JP TT $=J P T F-X$}

Leia-se: Jogo de palavras no texto-alvo = Jogo de palavras no texto-fonte Elemento(s) constitutivo(s) do Jogo de palavras no texto-fonte. Essa estratégia é semelhante à estratégia JP TF = JP TT apresentada por Delabastita (1996), com a diferença de que nessa proposta "X" representa elemento(s) constitutivo(s) do JP no texto-fonte que é/são suprimido(s) no texto da língua-alvo.

Dois JPs traduzidos por meio dessa estratégia são identificados no corpus de estudo, o JP "Concha" e o JP "Profondément", os quais são discutidos na sequência desta análise.

\section{JP Concha}

TF Afrodite, entronizada em sua concha. O estulto investigante ignora que chamam a vagina "concha". Concha, cona. Cunt, como o próprio inglês. Ele ri do jogo de palavras. A concha, a vulva, onde deixou todas as cordas.

TA Aphrodite, enthroned in her concha. The imbecilic detective doesn't know they call the vagina concha. "Cunt," as in English itself. He laughs at the play on words. The concha, the vulva, where he left the strings.

O JP "Concha" localiza-se no capítulo 24 do romance, e é proferido por Miguel Solera de Lara, momentos antes de pronunciar o JP "Orelhas", ou seja, o cenário onde é ambientado o JP "Orelhas" é também o da elaboração do JP 
"Concha". Miguel Solera de Lara encontra-se a bordo do navio Kaikoura, que o conduz à Inglaterra. Antes de jogar as orelhas extirpadas das moças ao mar, Miguel brinca com os sentidos da palavra "concha", o assassino relaciona-a à palavra "vagina", onde sempre deixava, nos corpos das suas vítimas, como um ritual macabro, uma corda do violino Stradivarius roubado da baronesa de Avaré.

O JP pode ser classificado como "homonímia", nos termos da definição apresentada por Delabastita (1996) e adotada nesta pesquisa, isto é, situação em que duas palavras apresentam grafias e sons idênticos e têm sentidos diferentes. Conforme se observa no texto do JP, a primeira ocorrência da palavra "concha" referese ao "invólucro de alguns moluscos", como a concha sobre a qual está entronizada a imagem de Afrodite, de acordo com a descrição de Miguel Solera de Lara.

O outro sentido da palavra "concha" é comentado por Miguel, que afirma, de maneira indeterminada, que as pessoas chamam de "concha" o órgão sexual feminino, conforme se verifica no trecho extraído do JP: "O estulto investigante ignora que chamam a vagina "concha".

No que concerne às estratégias de tradução empregadas na recriação do JP em inglês, observa-se que o trecho "Afrodite, entronizada em sua concha" é traduzido literalmente por "Aphrodite, enthroned in her concha".

$\mathrm{O}$ segundo trecho "O estulto investigante ignora que chamam a vagina 'concha" traduz-se por "The imbecilic detective doesn't know they call the vagina concha". Nesse trecho, o tradutor recria os sentidos dos elementos, sem, no entanto, dar muita atenção aos aspectos formais. É assim, por exemplo, que substitui "investigante" por "detective" (detetive) e "ignora" por "doesn't know" (não sabe).

O trecho seguinte "Concha, cona" é omitido no texto da língua-alvo; portanto, o trecho que na língua-fonte é "Concha, cona", no texto da língua-alvo é "vazio", cuja representação neste artigo é " $\varnothing$ ”. De acordo com o que se observa nas estratégias adotadas até o segundo trecho, a tradução reconstrói o JP usando o elemento "concha" com o qual é construído o JP no texto-fonte. Isso significa, portanto, que até o segundo trecho a estratégia de tradução usada é compatível com JP TF = JP TT, conforme apresentado por Delabastita (1996).

Ocorre, no entanto, que, embora o elemento principal do JP seja a palavra "concha", outros elementos estão presentes e concorrem para a sua realização, como a palavra "cona" e a repetição da palavra "concha". Observa-se, entretanto, que esses elementos são omitidos no texto da língua-alvo, alterando, desse modo, a estratégia JP TF = JP TT, segundo a qual o JP no texto-fonte é igual ao JP no texto-alvo. Em razão disso, o procedimento tradutório observado em relação ao JP em análise é compatível com a estratégia proposta neste estudo, isto é, a estratégia JP TT $=\mathbf{J P}$ TF $-\mathbf{X}$, em que $\mathrm{X}$ representa elementos constitutivos do JP do texto-fonte que são omitidos no JP do texto-alvo.

Os trechos seguintes são traduzidos de forma muito próxima em relação ao texto-fonte. Em "Cunt, como o próprio inglês" o tradutor transcreve a palavra "cunt" e traduz literalmente o restante do trecho: "“Cunt," as in English itself "; o trecho seguinte é traduzido literalmente, pois "Ele ri do jogo de palavras" é traduzido por "He laughs at the play on words". 
No último trecho observa-se a recuperação semântica de quase todos os elementos, exceto da palavra "todas", já que "A concha, a vulva, onde deixou todas as cordas" é traduzido por "The concha, the vulva, where he left the strings", e não "The concha, the vulva, where he left ALL the strings".

Conforme se observa, portanto, o JP é traduzido de modo semelhante ao que se procede quando utilizada a estratégia JP TF = JP TT (Delabastita, 1996); ou seja, traduz-se o trecho onde se encontra o JP. Contudo, o JP propriamente dito é reproduzido (e não traduzido) no texto-alvo com forma semelhante à encontrada no texto-fonte. Nesse JP são reproduzidas as palavras "concha", "cona" e "cunt", presentes na elaboração do JP inicial. Entretanto, como já observado, há elementos constitutivos do JP no texto-fonte que são eliminados no texto-alvo, são eles a palavra "cona" e a repetição da palavra "Concha", na segunda linha do texto-fonte. Assim, propõe-se como estratégia de tradução JP TT = JP TF - X.

O segundo JP a ilustrar a estratégia JP TT = JP TF - X é o JP "Profondément", sobre o qual se discorre a partir deste ponto.

\section{JP Profondément}

TF

O francês é uma língua curiosa: "profondément, profond dément".

- Cut... "couper profondément"

French is a curious language: "profond dément."

Abre o quarto capítulo de O Xangô de Baker Street a descrição da cena em que o assassino contumaz Miguel Solera de Lara realiza a leitura do livro Précis d'anatomie et de dissection, de $\mathrm{H}$. Beaunis. Interessa-lhe especialmente a parte do livro sobre dissecação. $\mathrm{O}$ exterminador sanguinário de moças que lhe parecem prostitutas é criativo e não quer repetir nas próximas vítimas o golpe que matou a primeira, é por essa razão que, "na madrugada abafada e úmida do seu quarto quase monástico" (SOARES, 1995, p. 37), lê vorazmente a parte sobre dissecação, onde depara com o trecho em que se insere o JP, isto é, a parte em que H. Beaunis orienta sobre o modo de separar a pele do músculo por meio de uma incisão profunda na pele. A leitura, realizada à luz de lamparina, tem como objetivos principais aperfeiçoar os golpes que pretende dar em suas próximas vítimas, bem como ajudá-lo a retirar, em alguns casos, os seus órgãos.

O trecho em que se situa o JP é construído com palavras de dois idiomas, português e francês; todavia, o JP propriamente dito envolve apenas palavras da língua francesa. Seus principais elementos são as palavras "profondément"e "profond dément" e, de acordo com o que propõe Delabastita (1996), trata-se de um JP vertical, ou seja, aquele cujos elementos encontram-se na mesma porção de texto.

O primeiro elemento do JP, "profondément" (profundamente), é um advérbio da língua francesa e, no texto do JP, refere-se ao modo de cortar, isto é, afirma que o corte na pele deve ser "profundo" e que, portanto, deve-se cortar "profondément" (profundamente). 
O segundo dos dois elementos é composto pelas palavras francesas "profond" (profundo/a) e "dément" (demente). A primeira é um adjetivo em francês e se refere ao oposto de "raso", "superficial". O correspondente da segunda palavra é "demente" em português e pode ser usado tanto como substantivo quanto adjetivo e se refere àquele ou àquela que se tem por louco(a); o(a) que sofre de algum distúrbio mental; que é acometido(a) por algum tipo de "demência" (DICIONÁRIO ONLINE DO PORTUGUÊS, 2015).

A tradução do JP ocorre da forma como segue: o primeiro trecho é composto de apenas três palavras no texto da língua-fonte, uma em português e duas em francês. A primeira palavra é traduzida literalmente, enquanto as outras duas são transcritas no texto da língua-alvo: "Cortar... couper profondément" é traduzido como "Cut... "couper profondément".

O segundo trecho é traduzido de forma literal, pois seus elementos são traduzidos por equivalentes "diretos" (tradução prima facie) no texto-alvo. Desse modo, tem-se "O francês é uma língua curiosa" traduzido por "French is a curious language".

A última parte realiza o JP propriamente dito por meio dos elementos "profondément, profond dément". A tradução omite o primeiro segmento "profondément" e transcreve o segundo "profond dément". Portanto, "profondément, profond dément" do texto-fonte é substituído por "profond dément" no texto-alvo.

Desse modo, o que se observa é que o JP é reconstruído no texto-alvo com os elementos de sua elaboração no texto-fonte, de maneira que os elementos não são traduzidos propriamente, mas transcritos em sua forma original. Esse procedimento é compatível com a estratégia JP TF = JP TT (Delabastita, 1996). Ressalta-se, no entanto, que nem todos os elementos que constituem o JP na língua-fonte são transcritos no texto da língua-alvo, já que a repetição da palavra "profondément" no segundo trecho do texto-fonte é omitida no texto-alvo. Por essa razão, a estratégia de tradução observada é compatível com JPTT = JP TF - X, em que X representa a omissão de elementos constitutivos do JP do textofonte no texto-alvo, conforme se propõe nesta pesquisa.

Face ao exposto, as quatro estratégias de tradução discutidas acima representam, portanto, a proposta deste estudo para a ampliação do modelo (quadro de estratégias) de Delabastita (1996), conforme indicado no início desta seção.

\section{Considerações finais}

Este trabalho teve como objetivo principal analisar o tratamento dado aos JPs do romance O Xangô de Baker Street pelo seu tradutor para a língua inglesa. Para isso utilizou o aparato teórico-metodológico da LC, realizando um estudo "direcionado pelo corpus", conforme discutido por Tognini-Bonelli (2001). Além disso, o estudo partiu de dois objetivos específicos, o primeiro foi verificar se as estratégias empregadas na tradução dos JPs do romance estudado foram capazes de recriar seus efeitos e sentidos na língua-alvo. Os resultados indicaram que as 
estratégias usadas pelo tradutor foram capazes de recriar seus efeitos e sentidos, mas em parte. Isso porque foi possível observar que entre os JPs traduzidos por meio de estratégias capazes de recriar o efeito e o sentido na língua-alvo encontram-se os JPs do corpus que são elaborados principalmente com base em aspectos polissêmicos, isto é, aqueles que se baseiam em uma realidade extralinguística (DELABASTITA, 1996), e não em aspectos ditos "linguísticos", como os trocadilhos, por exemplo.

Por sua vez, os JPs elaborados com base em aspectos linguísticos não foram traduzidos, em todos os casos, mantendo-se, efeito e sentido. A recriação desse tipo de JP mantendo-se efeito e sentido deu-se apenas em três situações: quando havia expressão equivalente na língua-alvo; quando, não havendo expressão equivalente, o tradutor adicionou uma explicação; ou quando o tradutor realizou uma alteração no texto com o objetivo de viabilizar a tradução de um JP. São exemplos de JPs "linguísticos" traduzidos com base na primeira situação: "Concha" e "Profondément"; com base na segunda, os JPs "Caipirinha" e "Viado só amanhâ"; enquanto o JP "Esperidiana” foi traduzido de acordo com a terceira situação.

O primeiro objetivo específico baseou-se na hipótese de que não é possível garantir, em todos os casos de tradução de JPs, que os seus efeitos e sentidos funcionem igualmente, na língua-alvo. Essa hipótese foi confirmada, já que, como se discutiu, nem todos os JPs analisados tiveram seus efeitos e sentidos reconstruídos de forma cumulativa (efeitos mais sentidos) na língua-alvo.

O segundo objetivo específico do estudo propôs a revisão do modelo de Delabastita (1996) e sua ampliação por meio da inserção de novas estratégias de tradução de JPs. Esse objetivo considerou a hipótese de que o modelo apresentado por Delabastita (1996) não daria conta de todas as estratégias de tradução usadas pelo tradutor do romance O Xangô de Baker Street para o inglês. Nesse sentido, de acordo com a discussão apresentada, os resultados mostraram que sete JPs do romance foram traduzidos por meio de estratégias que se diferenciam daquelas apontadas por Delabastita (1996), o que comprova a hipótese mencionada. Sendo assim, este estudo propõe a ampliação do quadro apresentado por Delabastita (1996) e o faz por meio de quatro estratégias de tradução, descritas a partir dos procedimentos observados na tradução dos JPs do romance O Xangô de Baker Street por Clifford Landers. São elas: a estratégia JP $\rightarrow$ JP + EXPL, isto é, Jogo de palavras $\rightarrow$ Jogo de palavras + Explicação; a estratégia $\mathbf{J P} \rightarrow \mathbf{A T} \rightarrow \mathbf{J P}$, ou seja, Jogo de palavras $\rightarrow$ Alteração textual $\rightarrow$ Jogo de palavras; a estratégia JP TT $=$ JP TF + EXPL, em que o Jogo de palavras no texto-alvo = Jogo de palavras no texto-fonte + Explicação; e a estratégia JP TT $=\mathbf{J P} \mathbf{T F}-\mathbf{X}$, onde se observa que o Jogo de palavras no texto-alvo = Jogo de palavras no texto-fonte - Elemento(s) constitutivo(s) do Jogo de palavras no texto-fonte.

Por fim, espera-se que este trabalho venha a contribuir com os estudos da tradução, ao propor estratégias novas de tradução de JPs com base em um corpus literário, bem como ao evidenciar a adequação da LC como abordagem viável ao campo da tradução, capaz de reunir em um só estudo o linguístico e o literário. 
Agradecimento: Sou grato à Profa. Dra. Stella Esther O. Tagnin, da Universidade de São Paulo, pela cuidadosa orientação da tese de doutorado da qual resulta este artigo.

Notas

1. São de minha autoria todas as traduções neste artigo, salvo quando especificado. No original: "Wordplay is the general name for the various textual phenomena in which structural features of the languages(s) used are exploited in order to bring about a communicatively significant confrontationof two (or more) linguistic structures with more or less similar forms and more or less different meanings".

2. No original: "[...] in the beginning was the pun [...]".

3. No original: "[...]natural to the human mind".

4. Conforme apresenta-se na seção 4, os estudos direcionados pelo corpus (em oposição aos estudos baseados em corpus) (TOGNINI-BONELLI, 2001) não partem de hipóteses previamente elaboradas pelo pesquisador, uma vez que é o próprio corpus que fornece elementos para a sua elaboração durante a pesquisa. Dito isto, ressalta-se, as hipóteses mencionadas nesta introdução foram construídas ao longo da pesquisa (e não previamente), a partir de elementos observados durante a exploração do corpus de estudo.

5. No original: "There is indeed a lot more at stake than just the question is wordplay translatable? For a start, any answer that this question may prompt is bound to be theoretically biased insofar as it will depend on the type of translation one has in mind (in terms of kinds and degrees of equivalence, as well as of genres and communicative situations), but also on the speaker's own position vis-à-vis the actual business of translation (whether one is speaking as a teacher of translation, as a practitioner, a critic, a theorist, a historian, a philosopher of language)".

6. No original: "[...] coping with puns, [...]".

7. De acordo com Nida (1964), o tradutor tem à sua disposição dois procedimentos tradutórios básicos. São eles, a "equivalência formal", procedimento por meio do qual se procura reconstruir literalmente a "forma" e o "conteúdo" de uma mensagem original; e a "equivalência dinâmica", procedimento que tem como objetivo criar no texto traduzido um "efeito" semelhante (equivalente) ao do original. Sobre "equivalência formal" e "equivalência dinâmica", confira também Rodrigues (2000).

8. Literalmente: O que é preto e branco e vermelho/lido (ler) em todos os lugares?

9. No original: "[...] to register-based humour where long stretches had to be edited by the subtitler, but also (verbo-pictorial) wordplay involving much smaller units".

10. Em virtude da limitação de espaço, não serão apresentados exemplos da aplicação das estratégias.

11. No original: "An approach or a methodology for studying language use. It is an empirical approach that involves studying examples of what people have actually said, rather than hypothesizing about what they might or should say. [...] Corpus Linguistics also makes extensive use of computer technology, which means that data can be manipulated in ways that are simply not possible when dealing with printed matter".

12. A chavicidade de um item caracteriza-se pela sua frequência estatística no corpus de estudo em relação a um corpus de referência. Assim, tende a ter maior valor de chavicidade o item que apresenta frequência estatística alta no corpus de estudo e baixa no corpus de referência. 
13. No original:"In Samba, set in 1886 Rio de Janeiro, when the redoubtable English detective arrives to pay a visit, a house slave's ignorance of English surnames is reflected in her failure to understand Sherlock's 'I'm Holmes', which she hears as " $\mathrm{Eu}$ sou homem, eu sou homem." Que ele é homem eu já sei"("I'm a man, I'm a man". "I already know he's a man'). Can the humor be salvaged in translation? 'I'm homo' was rejected immediately, not for reasons of prudery but because the slang term for a homosexual wasn't registered until the third decade of the $20^{\text {th }}$ century. Then the inspiration (?) 'I'm home'struck, which allows the slave to say, 'Does he think he lives here?' The meaning goes, the humor (hopefully) stays".

14. In A Samba for Sherlock, the crucial word in the denouement was totally different in Portuguese and in English. This forced a key modification in the TL: the serial killer taking flaps of skin instead of cutting off his victims' ears. Subsequent changes were then necessitated - for instance, a wag saying, 'Não há de ser por ganância. Nenhuma das vítimas usava brincos' (It can't be from greed. Neither of the victims wore earrings), became 'It can't be because he's an art collector. Neither of the victims was tattooed'.

15. No original: "Another way to impart essential information already known to the SL reader is interpolation. In its basic form it is nothing more than adding a parenthetical word or phrase, as unobtrusively as possible [...]".

16. No original: "Everything following pai-de-santo in the first sentence is an accretion, as is the explanatory phrase 'a priestess'. Both are examples of interpolation. If done carefully and with consideration for the rhythmic flow of language, interpolation can be imperceptible".

17. No original: "A strategy that is rarely mentioned even though it can achieve interesting results is that of extending the translation of the transformed idiom by inserting some additional explanatory information".

\section{Referências}

AGUIAR, S. M. As vozes de Chico Buarque em inglês: Tradução e Linguística de Corpus. Tese de Doutorado, São Paulo. Universidade de São Paulo, 2010. Disponível em: $<$ http://www.teses.usp.br/teses/disponiveis/8/8147/tde-20042011-150715/pt-br. php>. Acesso em: 10 de outubro de 2014.

ANTUNES, B. Notas sobre a tradução literária. In: Alfa: Revista de Linguística. Vol. 35, 1991, p. 1-10. Disponível em: <http://seer.fclar.unesp.br/alfa/article/ view/3854/3550>. Acesso em: 06 agosto de 2014.

ARROJO, R. Oficina de tradução: a teoria na prática. São Paulo: Editora Ática, 2002.

ASIMAKOUlAS, D. Towards a Model of Describing Humour Translation. A Case Study of the Greek Subtitled Versions of Airplane! and Naked Gun. In: Meta. Vol. 49, n. 4. St. Jerome Publishing, 2004, p. 822-842. Disponível em: <https://www. stjerome.co.uk/tsa/abstract/6838/>. Acesso em 01 de agosto de 2013.

BERBER SARDINHA, T. Linguística de Corpus. São Paulo: Manole, 2004.

BOWKER, L.; PEARSON, J. Working with Specialized Language: a practical guide to using corpora. London: Routledge, 2002.

CHIARO, D. Investigating the perception of translated Verbally Expressed Humour on Italian TV. In: ESP Across Cultures. Vol. 1. St. Jerome Publishing, 2004, p. 3552. Disponível em: <https://www.stjerome.co.uk/tsa/abstract/ 7048/>. Acesso em: 09 de fevereiro de 2015.

CHIARO, D. The language of jokes: analyzing verbal play. London: Routledge, 1992.

CINTRÃO, H. P. Notas para um estudo da tradução literária do espanhol no Brasil. In: Anais do V Congresso Brasileiro de Hispanistas/I Congresso Internacional da 
Associação Brasileira de Hispanistas. Vol. 1. Belo Horizonte: UFMG, 2009, p. 2723-2731. Disponível em: <http://www.letras.ufmg.br/espanhol/Anais/anais_ paginas\%20_2502-3078/Notas \%20para\%20um\%20estudo.pdf>. Acesso em: 15 de setembro de 2014 .

DELABASTITA, D. (Introduction). The translator: studies in intercultural communication-Wordplay \& Translation. Vol. 2. N. 2. Manchester: St. Jerome Publishing, 1996.

DELABASTITA, D. There's a double tongue. An investigation into the translation of Shakespeare's wordplay. Amsterdam \& Atlanta: Rodopi, 1993.

DICIONÁRIO ONLINE DO PORTUGUÊS, 2015. Disponível em: <http://www. dicio.com.br/>. Acesso em: 01 de fevereiro de 2015.

JAKOBSON, R. Os aspectos linguísticos da tradução. 20. ed. In: Linguística e comunicação. São Paulo: Cultrix, 1995.

LAGES, S. K. Walter Benjamin: tradução e melancolia. São Paulo: Edusp, 2002.

LAMBERT, J. Literary translation. Research issues. In: BAKER, M. (Dir.). Routledge Encyclopedia of Translation Studies. London/ New York: Routledge, 1998. p. 130133.

LANDERS, C. E. Literary translation: a practical guide. New York: Multilingual Matters, 2001.

MILTON, J. Tradução: teoria e prática. 2 ed. São Paulo: Martins Fontes, 1998.

NIDA, E. A. Toward a science of translating. Leiden: E. J. Brill, 1964.

REDFERN, W. Traduction, Puns, Clichés, Plagiat. In: DELABASTITA, D. (Ed.). Traductio. Essays on punning and translation. United Kingdom: St. Jerome Publishing, 1997, p. 261-269.

REISS, K.; VERMEER, H. J. Fundamentos para una teoría funcional de la traducción. Trad. Sandra Reina e Celia de León. Madrid: Akal, 1996.

RODRIGUES, C. C. Tradução e diferença. São Paulo: Editora UNESP, 2000.

SCOTT, M. Wordsmith Tools 6.0. Oxford: Oxford University Press, 2012.

SOARES, J. O Xangô de Baker Street. São Paulo: Companhia das Letras, 1995. 1997.

TAGNIN, S. E. O. O jeito que a gente diz: combinações consagradas em inglês e português. São Paulo: Disal Editora, 2013

TOGNINI-BONELLI, E. Corpus Linguistics at work. Amsterdam: John Benjamins, 2001.

TOURY, G. What Is It That Renders a Spoonerism (Un)translatable? In: DELABASTITA, D. (Ed.). Traductio. Essays on punning and translation. United Kingdom: St. Jerome Publishing, 1997, p. 271-291.

VEISBERGS, A. The Contextual Use of Idioms, Wordplay, and Translation. In: DELABASTITA, Dirk (Ed.). Traductio. Essays on punning and translation. United Kingdom: St. Jerome Publishing, 1997, p. 155-176. 